\title{
Mercedes Fuertes
}

\section{Los órganos municipales de carácter complementario}

SUMARIO: I. LA REGULACION DE LOS «ORGANOS COMPLEMENTARIOS» EN LA LEY REGULADORA DE LAS BASES DE REGIMEN LOCAL. II. LA INCIDENCIA DE LA SENTENCIA DEL TRIBUNAL CONSTITUCIONAL DE 21 DE DICIEMBRE DE 1989. CRITICA. III. LA ORGANIZACION COMPLEMENTARIA EN LOS REGLAMENTOS ORGANICOS. IV. LOS ORGANOS COMPLEMENTARIOS QUE SE MENCIONAN EN LA SUPLETORIA LEGISLACION ESTATAL. 1. Los Concejales delegados. 2. Los representantes del Alcalde. 3. Las Comisiones Informativas. A) Naturaleza. B) Clases de Comisiones. C) Creación. D) Composición. E) Funcionamiento. F) Extinción. 4. La Comisión Especial de Cuentas. 5. Las Juntas Municipales de Distrito. 6. Los Consejos sectoriales. 7. Los órganos desconcentrados y descentralizados. V. LA LEGISLA. CION AUTONOMICA. 1. Las especialidades de la legislación catalana. 2. Las especialidades de la legislación murciana. 3. La legislación de la Comunidad canaria. VI. ADDENDA SOBRE LA APLICACION DE LA NUEVA LEY DEL REGIMEN JURIDICO Y DEL PROCEDIMIENTO COMUN.

\section{LA REGULACION DE LOS «ORGANOS COMPLEMENTARIOS» EN LA LEY REGULADORA DE LAS BASES DE REGIMEN LOCAL}

El análisis de los denominados «órganos complementarios» de las Corporaciones locales pone de manifiesto que la Ley reguladora de las bases del régimen local (en adelante, LB) no sólo pretendió acomodar el régimen local a las exigencias constitucionales, derivadas de modo fundamental del título VIII, sino también establecer un amplio y extenso marco de regulación, que sirviera y atendiera las variadas realidades de Entidades locales que coexisten en el territorio español. Esta práctica intención no era nueva en la legislación local, pues desde el Estatuto de Calvo Sotelo se admitió, aunque parcamente, el posible re- 
conocimiento de regímenes especiales frente al uniforme y general modelo de la organización municipal. Sin embargo, como es conocido, sólo de forma esporádica se había llevado esta posibilidad a la realidad. En este sentido, la LB, aunque se ampara en la necesidad de conseguir cierto grado de uniformidad a la hora de definir unos idénticos órganos de gobierno en la práctica totalidad de los Ayuntamientos, calificados por ello dichos órganos como «necesarios», no dudó en reconocer el posible establecimiento de una organización complementaria.

En distintos párrafos de la propia Exposición de motivos, se puede leer que la ley establece «las competencias, principios, criterios y directrices que guían la aplicación práctica de la norma en su conjunto de forma abierta a la realidad y a las necesidades del presente», así como que «en el plano de la organización interna de las Entidades locales... procede reconocer la primacía del interés de la acomodación de aquélla a las características específicas de éstas». Las concretas dimensiones de los Ayuntamientos, la prestación de mayores servicios o los principios de gestión, que en cada caso predominen, incidirán en la creación de otros nuevos órganos llamados a apoyar y facilitar las funciones de los órganos exigidos de modo general en la LB.

Este concepto de «complementariedad», como no necesario a los efectos de uniformidad mínima en todo el territorio y supeditado a las particulares exigencia de gestión de la Corporación local, es el que reconocía inicialmente la propia $L B$ en su artículo 20 . Se admitía que los municipios, en sus reglamentos orgánicos, establecieran otros órganos «complementarios a los anteriores», por tanto, sin más parámetros que, de un lado, el respeto a la regulación de los órganos necesarios y, de otro, la existencia de circunstancias o motivos que justificaran la conveniencia o la oportunidad de su creación y su particular configuración. También se reconocía la posible existencia de normativa de la Comunidad autónoma sobre la organización municipal, pero sólo se admitía su aplicación supletoria (en el párrafo segundo del art. 20 de la LB), al primar en toda esta regulación la idea de la autonomía municipal.

\section{LA INCIDENCIA DE LA SENTENCIA DEL TRIBUNAL CONSTITUCIONAL DE 21 DE DICIEMBRE DE 1989. CRITICA}

No debe ocultarse que este panorama inicial de reconocimiento de la autonomía municipal se alteró de forma radical con la sentencia del Tribunal Constitucional de 21 de diciembre de 1989. El Tribunal entendió que la supletoriedad de las normas de las Comunidades autó- 
nomas sobre el régimen de organización municipal conculcaba el marco de distribución de competencias establecido, de modo fundamental, en la regla 18 del artículo 149.1 de la Constitución. En virtud de esta regla de distribución de competencias, el Tribunal declaró, a lo largo del fundamento jurídico $60^{\circ}$, que la LB negaba un ámbito normativo al legislador de la Comunidad autónoma, cosa que no puede admitirse al releer la LB pues el propio artículo 20 reconocía que «las leyes de las Comunidades autónomas sobre Régimen Local podrán establecer una organización municipal complementaria». El Tribunal entendió no obstante que era improcedente que prevaleciera el Reglamento Orgánico del específico Ente local sobre la regulación que pudiera desarrollar dicha Comunidad autónoma, como continuaba el párrafo segundo del mismo artículo 20 de la LB.

Sin abundar en la crítica a este razonamiento, pues recoge esta misma revista brillantes análisis a los que me remito (en especial, la presentación que realiza el profesor SOSA WAGNER, así como el trabajo del profesor PAREjo ALFONSO), a mi juicio, la respuesta al conflicto de prevalencia del Reglamento Orgánico sobre la legislación de la Comunidad autónoma no debería haberse apoyado en el artículo 149.1.18 de la Constitución, que sólo alude a la distribución de competencias entre el Estado y la Comunidad autónoma. Por tanto, excluye cualquier distribución con la Administración local, que debe resolverse por otros parámetros. La contestación a las alegaciones de las Comunidades autónomas debería haber partido del propio reconocimiento de la autonomía municipal que realiza la Constitución. De ahí, extraer sus conocidas consecuencias, en particular, destacar que uno de los elementos básicos de la misma, como de modo tradicional se estudia, es la autonomía organizativa. ¿Puede mantenerse que persista si se supedita el ámbito de libre organización a las prescripciones de la Comunidad autónoma? A mi juicio, debería contestarse de modo negativo este interrogante. Si la Comunidad autónoma impone con sus normas la organización complementaria de las Corporaciones locales, no sólo niega el reconocimiento de un marco de autonomía a las Entidades locales sitas en su territorio, sino que también excluye la existencia de distintas necesidades organizativas dentro de la variedad de caracteres de las mismas.

Por tanto, a mi entender, junto a los órganos calificados de necesarios, que responden a criterios uniformadores en todo el territorio, no debería negarse a los Ayuntamientos la facultad de resolver de modo independiente otras soluciones o propuestas de gestión y organización, más acordes y adecuadas con sus específicas y singulares particularidades. La imposición de criterios preferentes por la Comunidad autónoma quiebra esta libertad organizativa que debería ser amplia ante las grandes diferencias que existen entre los Municipios españoles. El 
excesivo número de Municipios, como critica de modo unánime toda la doctrina, no puede coexistir con pretensiones de similar organización.

Pero, además de estas razones apoyadas en el propio texto constitucional, un importante argumento que no debe olvidarse a favor de la autonomía organizativa de los Municipios es el reconocimiento que realiza de la misma la Carta europea de autonomía local, ratificada íntegramente por España sin reserva alguna. En su artículo 6 declara que «sin perjuicio de las disposiciones más generales creadas por la Ley, las Entidades locales deben poder definir por sí mismas las estructuras administrativas internas con las que pretenden dotarse, con objeto de adaptarlas a sus necesidades específicas y a fin de permitir una gestión eficaz». Los términos son suficientemente claros. Debe respetarse un ámbito de autonomía para que los Entes locales estructuren sus órganos de conformidad con sus necesidades. La existencia de legislación de la Comunidad autónoma no disminuirá dicha autonomía si se declarara su carácter supletorio, como con claridad establecía la redacción original del artículo 20.2 de la LB. Por el contrario, la sujeción, que ha consagrado el Tribunal Constitucional, de los Reglamentos Orgánicos de los Municipios a dicha legislación autonómica sí restringe la autonomía municipal.

El Tribunal Constitucional deberia haber encontrado las armas defensivas ante los ataques realizados por las Comunidades autónomas sobre la autonomía organizativa tanto en la interpretación del propio texto constitucional, en el respeto al concepto de autonomía municipal, como en los compromisos derivados de la Carta europea de autonomía local, que no pudieron aducir los propios Municipios ante el incomprensible impedimento de negar a los mismos presencia en los procesos constitucionales, cuando cuestiones tan trascendentales para ellos se ventilan.

En conclusión, el estudio de los órganos complementarios de las Corporaciones locales debe fundarse en el propio Reglamento Orgánico del Municipio, como reconoce la LB, pero además, tras la sentencia del Tribunal Constitucional, este reglamento deberá respetar en todo caso e integrar en su seno la legislación de la Comunidad autónoma, si existe. En defecto de Reglamento Orgánico, se estará a lo que disponga la legislación de la Comunidad y, en su defecto la legislación supletoria del Estado que, en la actualidad, se recoge en los artículos 119 y siguientes del Reglamento de organización, funcionamiento y régimen jurídico de las Corporaciones locales (en adelante, ROF).

Sin embargo, desde un punto de vista práctico, y tras la lectura de la legislación autonómica, se comprueba que la alteración del orden de prelación de fuentes al regular la organización municipal, provocada por la sentencia del Tribunal Constitucional, sólo tiene eficacia en 
una Comunidad autónoma, a saber, Cataluña. De las cuatro Comunidades autónomas que han promulgado disposiciones especiales sobre el régimen local, tres de ellas, como con posterioridad veremos, no han sujetado a los Municipios radicados en el territorio de la Comunidad a sus prescripciones (incluso habiéndose promulgado alguna de estas normas con posterioridad a la sentencia del Tribunal Constitucional), bien porque consideraban que no existían especialidades organizativas (caso de la Ley foral navarra), bien porque entendieron que la autonomía municipal ha de conducir a reconocer la organización municipal que libremente se cree y, sólo supletoriamente, aplicar la legislación autonómica (caso de Murcia y Canarias). Por tanto, sólo en Cataluña los Ayuntamientos han de integrar en su Reglamento Orgánico las prescripciones organizativas establecidas.

Esta consideración práctica me ha conducido a no utilizar el orden de prelación de fuentes resultantes de la sentencia como esquema, por lo que dejo para el último epígrafe el análisis de las especialidades recogidas en la legislación de las Comunidades autónomas. Por ello comienzo con un recordatorio relativo a la posible organización complementaria, que pueden establecer las Corporaciones locales, y comento, en segundo lugar, la legislación supletoria dictada por el legislador estatal que, como se ha leído, sólo se tendrá en cuenta en caso de inexistencia de un Reglamento Orgánico Municipal y de norma de la Comunidad autónoma.

\section{LA ORGANIZACION COMPLEMENTARIA EN LOS REGLAMENTOS ORGANICOS}

Como hemos visto, la LB y la Carta europea de autonomía local reconocen a los Municipios la libertad de definir su estructura y organización, con el debido respeto a la organización necesaria. Por tanto, en sus Reglamentos Orgánicos, los Ayuntamientos gozan de autonomía para crear órganos que coadyuven al desarrollo de las funciones municipales.

Atendiendo a sus propias necesidades, así como a las técnicas e instrumentos de organización administrativa, podrán establecer nuevos órganos ya individuales, ya colegiados; de carácter consultivo, de control o con funciones directivas; con facultades delegadas o transferidas; de participación ciudadana o de mero carácter técnico, etc. Las posibilidades de organización son múltiples, sólo dependientes, como ya se ha notado, de las especiales dimensiones del Municipio, sus criterios de gestión, así como de la imperativa configuración que realiza la LB de las funciones del Alcalde, de los Tenientes de Alcalde y del Pleno del Ayuntamiento (órganos necesarios, junto a la Comisión de 
Gobierno en los Municipios con más de cinco mil habitantes), que no podrán verse afectadas.

Sin embargo, a mi juicio, debe reconocerse una excepción al respeto de la normativa sobre los órganos necesarios. Entre las atribuciones del Alcalde que enumera el artículo 21 de la LB se encuentran la facultad de «convocar y presidir las sesiones del Pleno, de la Comisión de Gobierno y de cualesquiera otros órganos complementarios» [letra $c)$ ]. Con excepción del supuesto de las Comisiones informativas que, como se leerá con posterioridad, deben ser presididas por el $\mathrm{Al}$ calde o la persona que éste designe, al respetar su composición la distribución de fuerzas del Pleno del Ayuntamiento, si se reconoce autonomía municipal para crear otros órganos complementarios, no parece ajustado que se limite en todo caso el régimen de convocatoria y presidencia de dichos órganos. El Reglamento Orgánico, al regular un nuevo órgano municipal, podrá establecer las normas para la válida convocatoria que tenga como oportunas, así como designar a otra persona para que realice las funciones de presidencia distinta al Alcalde. Estos elementos integran el ámbito de autonomía de organización que no debe verse restringida por dicha norma genérica.

En fin, lo que en todo caso debe recordarse es que queda a la imaginación del Pleno del Ayuntamiento el establecimiento y la configuración de los órganos complementarios, que apoyen la administración del Municipio.

\section{LOS ORGANOS COMPLEMENTARIOS QUE SE MENCIONAN EN LA SUPLETORIA LEGISLACION ESTATAL}

A falta de hallazgos organizativos por la Corporación local, y siempre que no exista normativa de la Comunidad autónoma de aplicación preferente, el Reglamento Orgánico podrá acoger las pautas de organización que, de modo supletorio, establece el ROF en su artículo 119, aplicable también en aquellos Ayuntamientos que no aprueben un reglamento de organización. Pero, antes de aludir a las mismas, no debe ocultarse una precisión previa, que ya ha sido destacada por la doctrina. Me refiero a la inclusión de la «Comisión especial de cuentas» en esta lista del artículo 119 que enumera los órganos complementarios. Sirva la referencia al «Manual de Derecho local» del profesor SoSA WAGNER, que desde un primer momento ha defendido el carácter de órgano necesario de dicha Comisión, en términos del citado autor, «incomprensiblemente alojada entre los órganos complementarios», ya que tanto el artículo 116 de la LB, como del propio ROF se deduce su existencia preceptiva. 


\section{Los Concejales delegados}

Una de las tradicionales técnicas de organización es la delegación de funciones, admitida también en la legislación local. Junto a la sustitución ope legis establecida en el artículo 21 del Texto refundido de las disposiciones en materia de régimen local (en adelante, TR), en virtud de la cual, ausente el Alcalde y sin expresa delegación, ejercerá sus funciones el Teniente Alcalde, el ROF sólo regula la posible delegación de algunas funciones encomendadas al Alcalde. ¿Se impide con ello que el Pleno del Ayuntamiento confíe de modo explícito alguna función a uno de sus miembros, distinto del Alcalde? Aun cuando nada se establece de modo explícito en la LB, no puede deducirse otra respuesta que la negativa. La configuración del Pleno del Ayuntamiento, la finalidad de sus facultades, sólo algunas delegables en la Comisión de Gobierno o en el Alcalde, así como el carácter presidencialista de la normativa relativa al Alcalde conducen a contestar de modo negativo a la cuestión planteada. Las atribuciones que el Pleno pueda delegar, sólo podrán corresponder a la Comisión de Gobierno o al Alcalde. Este, sin embargo, podrá delegar alguna de sus funciones a otros órganos o algún Concejal. Esta es la solución que, además, se desprende con claridad de los artículos 114 y siguientes del ROF.

El contenido y el objeto de la delegación, que nunca podrá comprender aspectos o materias declaradas indelegables por la LB (en particular, las mencionadas en el art. 21.3), se contienen también en el ROF. En concreto, en su artículo 43, donde se diferencian las delegaciones genéricas de las especiales. Las primeras pueden comprender materias o áreas determinadas e incluirán todas las potestades de dirección y gestión, así como la facultad de resolver los procedimientos, de dictar los actos administrativos resolutorios, aunque afecten a terceros. Por el contrario, sólo admite el ROF tres modalidades de delegaciones especiales, a saber, sobre un asunto o proyecto determinado, sobre la gestión interna de un servicio o la que afecte a un distrito o barrio específico (art. 43.5), es decir, admiten tanto delegaciones funcionales como de carácter territorial.

Los párrafos tercero y cuarto del mismo artículo 43 del ROF (a los que se remite el art. 120 en sede de la organización complementaria) admiten y regulan, de una forma confusa a mi juicio, la concurrencia de delegaciones genéricas y especiales sobre una misma materia $o$ asunto. El Alcalde puede delegar de modo especial en algún Concejal determinadas atribuciones aunque exista una delegación genérica en la Comisión de Gobierno, en un Teniente Alcalde o en otro Concejal. Este complejo régimen de concurrencia de delegaciones, quizá derive de la necesidad de no quebrar el brocardo delegatus delegari non po- 
test (que se recoge de modo explícito en el art. 117 del ROF). Ante la prohibición de que la Comisión de Gobierno o un Concejal delegue en otro alguna atribución especial de funciones delegadas por el $\mathrm{Al}$ calde, corresponde sólo a este órgano el ejercicio de las delegaciones. Pero, a mi juicio, de llevarse a cabo varias delegaciones, unas específicas o especiales y otras genéricas, el ejercicio de las mismas no parece que estará exento de conflictos. ¿No sería preferible organizar el particular ejercicio de las facultades inherentes a la materia delegada por el órgano que ha recibido la atribución genérica, que desgajar del mismo aspectos concretos encomendándoselos a otro órgano?

Existen además en el ROF dos precisiones en este régimen de concurrencia de delegaciones. Una, que no es necesario que el Concejal favorecido con una delegación especial en una materia, cuyas funciones han sido delegadas de modo genérico a la Comisión de Gobierno, pertenezca a la misma (incomprensible afirmación si se recuerda la necesaria coordinación y coherencia en el ejercicio de las funciones). Dos, en caso de existir dos delegaciones sobre un mismo asunto, una general y otra específica, a favor de dos Concejales, se reconoce al que posea las atribuciones genéricas las funciones de supervisión y control de la actividad del otro Concejal.

En todo caso, los conflictos en las delegaciones deberán resolverse atendiendo a los concretos Decretos del Alcalde, que deben contener tanto los asuntos delegados, como las facultades y las posibles condiciones a que se sujeta el ejercicio de la delegación (según establece el art. 44.1 del ROF).

Desde un punto de vista dinámico, la delegación comienza a tener efectos a partir del día siguiente a la firma del Decreto, salvo que en el mismo se disponga otra cosa (art. 44.2 del ROF). No se supedita por tanto ni a la publicación de la misma en el Boletín oficial de la provincia, ni a su conocimiento por el Pleno, requisitos necesarios establecidos en el ROF, pero que no condicionan la eficacia de la delegación.

Por último, se extingue o concluye la delegación, bien por la renuncia del Concejal, bien por la revocación de la delegación, según el artículo 120.2 del ROF. Sin embargo no deben excluirse otras posibles causas de extinción, como la desaparición del asunto delegado o de las causas que pudieron motivar la misma.

\section{Los RePResentantes del AlCAlde}

Distinto del supuesto de delegación de atribuciones, se reconoce también la posibilidad de que el Alcalde otorgue poderes de representación a un vecino en dos casos concretos. Uno, cuando existan «barria- 
das o poblados», que no tengan la consideración de Entidad local y estén separados del centro urbano (art. 20.1 del TR, que reitera el art. 122.1 del ROF). Dos, «cuando el desenvolvimiento del servicio así lo aconseje» (arts. 20.2 del TR y 122.2 del ROF).

Destaca, en primer lugar, que no exija que los poderes recaigan de modo necesario en un miembro de la Corporación local, sino únicamente, la condición de vecino en el «núcleo» donde se ejercerá la representación (art. 122.2 del ROF). En segundo lugar, los supuestos que justifican el poder de representación se delimitan de modo diverso. Mientras en el primer caso, la existencia de núcleos separados sólo depende de que el mismo no sea un Ente local, en el segundo, la discrecionalidad del Alcalde es mayor, pues la indeterminación del presupuesto (que «el desenvolvimiento del servicio así lo aconseje») deberá interpretarse y justificarse en cada caso de modo independiente.

En fin, como no podía ser de otro modo, la duración de la representación está anudada al mandado del Alcalde, aunque también éste puede revocarla libremente (núm. 3 del art. 122 del ROF).

\section{LAS COMISIONES Informativas}

\section{A) Naturaleza}

La específica naturaleza jurídica atribuida a las Comisiones informativas en el ROF, como órganos consultivos del Pleno del Ayuntamiento o de su Comisión de Gobierno, conduce a restringir las facultades de los Municipios para configurar muchos aspectos de las mismas, que deberán sujetarse a las prescripciones de dicho Reglamento, en particular, la participación de representantes de todos los grupos políticos, según establece el básico artículo 20.3 de la LB.

Así, en caso de crearse, sólo podrán ser órganos consultivos que realicen las funciones de información técnica de los asuntos o materias que se les presenten, al no reconocerles en ningún caso las facultades directoras y resolutorias (art. $123 \mathrm{del}$ ROF). Sin embargo, en caso de existir, adquieren una notable importancia al ser preceptivo su informe a toda resolución que adopte el órgano decisor, ya sea el Pleno o la Comisión de Gobierno del Ayuntamiento. Los preceptos que describen el desarrollo de las sesiones de estos órganos especifican la necesidad, con carácter previo a los debates, de que se lea el informe de la correspondiente Comisión informativa [sirva la lectura a los arts. 82 núms. 2 y 3, 93 ó 113.c) del ROF], requisito que sólo se excepciona cuando los asuntos tengan la consideración de urgentes. Pero, aun en este caso, la Comisión informativa tiene importantes facultades, pues puede exigir que, en la siguiente convocatoria del Pleno o de la Co- 
misión, se analice y controle la «urgencia» del debate que se realizó sin el preceptivo informe (art. 126.2 del ROF).

\section{B) Clases de Comisiones}

El ROF admite la creación de Comisiones permanentes y especiales (art. 124). Mientras las primeras atienden al ejercicio de las funciones del Pleno o de la Comisión de Gobierno cuando actúe con funciones delegadas del Pleno, teniendo por tanto todas las facultades generales de instrucción, comprobación, estudio destinadas a un mejor apoyo e informe de dichos órganos; las segundas se constituyen por el Pleno para el estudio y análisis de un asunto concreto, por lo que sus facultades estarán delimitadas en el acuerdo de creación. Además, tanto en unas como en otras, el Alcalde o la Comisión de Gobierno podrán delegar las funciones de instrucción e informe de asuntos o funciones de su competencia (art. 123.2).

\section{C) Creación}

Como órganos de apoyo al Pleno del Ayuntamiento sólo pueden ser creadas por este órgano, como expresamente recoge el ROF en su artículo 124, aunque no podría admitirse otra solución al considerar su naturaleza de órgano consultivo del Pleno.

Ya se trate de Comisiones permanentes o especiales, sólo podrán crearse mediante acuerdo expreso del Pleno, en el que se especificará la denominación, composición, asuntos o materias de su competencia, etc. De ahí que cualquier acto de creación de Comisiones de información realizado por otro órgano municipal podrá ser atacado como acto nulo de pleno derecho, por incompetencia manifiesta. En este sentido puede citarse la sentencia del Tribunal Supremo de 15 de enero de 1992 que, tras aceptar los pronunciamientos del Tribunal Superior de Justicia de la Comunidad canaria, declara nulos los acuerdos del Alcalde de creación de Comisiones de asesoramiento, que sólo posee, como declara explícitamente el ROF, legitimación para proponer al Pleno su creación (art. 124.2).

\section{D) Composición}

La específica naturaleza de estas Comisiones incide de modo importante en su composición, cuyas reglas tienen un carácter básico y necesario. En especial, todos los grupos políticos han de tener repre- 
sentación en la Comisión (art. 20.3 de la LB). El ROF va más allá, exige que la estructura de la Comisión refleje la fuerza política de cada grupo, es decir, la existencia de cierta proporcionalidad en su conformación [art. 125.b)]. Este aspecto ya había sido destacado por el Tribunal Constitucional en la sentencia de 6 de marzo de 1985 al declarar que:

«la composición no proporcional de las Comisiones informativas resulta inaceptable porque éstas son órganos sólo en sentido impropio y en realidad meras divisiones internas del Pleno municipal, carentes de competencias decisorias propias y cuya función se reduce a preparar las decisiones de aquél, estudiando e informando previamente los asuntos sobre los que debe resolver. En cuanto partes del Pleno deben reproducir, en cuanto sea posible, la estructura política de éste, pues, de otro modo, en efecto, no sólo se eliminaría toda participación de los Concejales de la minoría en un estadio importante del proceso de decisión (y sólo un formalismo que prescinda absolutamente de la realidad puede ignorar la trascendencia que en este proceso tiene la fase de estudio y elaboración de propuestas), sino que se hurtaría a la minoría incluso la posibilidad de participar con plena eficacia en el estadio final de la decisión, privándola del tiempo necesario para el estudio en detalle de los asuntos, o de la documentación que ello requiere, o de ambas cosas».

Estas mismas consideraciones han sido reiteradas por los Tribunales ante los que se ha llevado la impugnación de la composición de Comisiones informativas. En este mismo sentido, pueden leerse la sentencia de la antigua Audiencia Territorial de Zaragoza de 9 de marzo de 1988 o la sentencia del Tribunal Superior de la Comunidad Autónoma de Andalucía (Sala de Granada) de 7 de julio de 1989 que, incluso, declara que la proporcionalidad debe respetarse en todo caso y no admite que, para beneficiar la presencia de los grupos minoritarios, se quiebre la regla proporcional asignando menos representantes a otros grupos con mayor número de Concejales.

Aunque estas declaraciones no dejan lugar a otras soluciones, imponiendo en todo caso que la composición de las Comisiones informativas refleje con exactitud la regla proporcional que derive de la composición del Pleno del Ayuntamiento, a mi juicio, estos pronunciamientos son demasiado estrictos, por lo que no considero ociosas las siguientes observaciones.

En primer lugar, no debe confundirse la participación de todos los grupos políticos que integran la Corporación en los distintos órganos de la misma (como establece el art. 20.3 de la LB y que enlaza con los 
principios de representatividad establecidos en la Constitución), con la necesidad de que cada grupo traslade al seno de todos los órganos la fuerza de los votos que posee en el Pleno (como prescribe el ROF y han declarado de modo contundente las sentencias citadas). Resulta obvia la diferencia de matiz una cosa es la participación cualitativa de todos los grupos y otra, que dicha participación sea también cuantitativa. Pero continuemos con las observaciones.

En segundo lugar, y lo que realmente debe resaltarse, es que las Comisiones informativas no tienen facultades decisorias, sino meramente consultivas o informadoras, por lo que la fuerza de los votos, a mi juicio, no debe tener tanta trascendencia en su seno, donde las propuestas de resolución e informes que eleven al Pleno o a la Comisión de Gobierno podrán contener todas las matizaciones que crean oportuno realizar los distintos grupos políticos. La resolución y la decisión de los asuntos y materias la realizará el Pleno o, en su caso, la Comisión de Gobierno, por lo que, a mi entender, no tiene tanta relevancia que la Comisión informativa refleje la exacta distribución de votos del Pleno. Lo importante es que todos los grupos políticos tengan acceso a la instrucción de los expedientes, a las líneas de elaboración de los mismos, a manifestar su opinión en los informes finales.

En fin, criterios de buena organización podrían aportar ctras soluciones en las que se conjugaran la estructura participativa (pero lo menos numerosa posible para el mejor funcionamiento de la Comisión) con el reconocimiento, si se creyera necesario, del porcentaje de votos en los órganos decisores (cada representante o representantes de los grupos políticos podría, si en algún caso es necesario votar, poseer un número ponderado de votos), cosa que ocurre, como es conocido, en otras instancias (sirva como ejemplo la organización interna de las Cortes Generales, donde en la Junta de portavoces de los grupos parlamentarios, que tienen importantes funciones decisorias, están representados todos los grupos, que poseen su voto ponderado).

La designación de los respresentantes en la Comisión informativa corresponde, como es lógico, a cada grupo político, que por medio de su portavoz remitirá escrito al Alcalde o Presidente de la misma, quien dará cuenta al Pleno, para su aprobación, de la definitiva composición [letra $c$ ) del art. 125]. El Alcalde no tiene ninguna competencia sobre esta integración, de ahí que, como ha declarado la sentencia de la Audiencia Territorial de Burgos de 8 de julio de 1988, el Alcalde no puede cesar a Concejales que forman parte de las mismas. Las facultades del Alcalde con relación a las Comisiones se reducen a proponer su creación al Pleno del Ayuntamiento, al ser este órgano el que posee las competencias sobre la organización de las Comisiones; la designación corresponde a los grupos políticos. El hecho de que el Alcalde pueda revocar los poderes en otros supuestos, caso del Teniente Al- 
calde o de Concejales delegados, no puede traerse a colación o aplicarse por analogía, donde existe una explícita relación de delegación de facultades. (En el mismo sentido, pueden leerse las sentencias del Tribunal Supremo de 16 y 27 de enero de 1987.)

\section{E) Funcionamiento}

Aunque el ROF declara supletorias las reglas de funcionamiento del Pleno para el desenvolvimiento de las Comisiones informativas (art. 138), establece también algunas reglas de funcionamiento. Así, podrá reunirse en sesiones ordinarias (las que con carencia periódica haya establecido el Pleno en el acuerdo de constitución de la Comisión), extraordinarias (cuando lo solicite la cuarta parte de sus miembros) o urgentes. La convocatoria de la Comisión corresponde al Alcalde o, en su caso, al Concejal que presida la misma y deberá realizarse con, al menos, dos días de antelación a la fecha que se fije. Como toda convocatoria de órgano colegiado, deberá notificarse personalmente a sus miembro:s, así como incluir el orden del día a seguir (art. 134.3). Asimismo, para admitir la válida constitución será necesaria la presencia de la mayoría absoluta de sus miembros en la primera convocatoria y, en su defecto, será suficiente la concurrencia de tres miembros en la segunda, una hora más tarde (art. 135.1 del ROF).

La sesión se ajustará al orden del día propuesto, poseyendo el Presidente las facultades de dirección y ordenación de los debates. Además, aunque tienen el carácter de secretas, según el artículo 227.2 del ROF, el mismo precepto admite que se facilite la audiencia de las asociaciones vecinales. En este sentido, entiendo debe darse también audiencia a las asociaciones de consumidores y usuarios existentes en el Municipio. Como es conocido, la Ley 26/1984, de 19 de julio, general para la defensa de los consumidores y usuarios establece con el carácter de preceptiva la audiencia a las asociaciones constituidas al amparo de dicha Ley cuando se regulen servicios de uso público, tarifas y precios de los mismos o a las «condiciones generales de los contratos de empresas que prestan servicios públicos en régimen de monopolio» [art. 22.2, letras $b$ ), d) y $e$ ) de dicha Ley]. No existe, a mi juicio, razón para no aplicar esta Ley precisamente en el ámbito municipal, donde también se regulan estas importantes cuestiones ciudadanas y donde adquieren su mayor relevancia.

Por último, el ROF establece que los informes deben ser aprobados con mayoría absoluta de los miembros presentes y, en caso de empate, resolverá el voto dirimente del Presidente. Como no podía ser de otro modo, los miembros que voten en contra podrán hacer constar su propuesta en el informe. 


\section{F) Extinción}

En principio, las Comisiones informativas de carácter permanente gozan de la misma vigencia que la Corporación que las creó, aunque el ROF parece admitir la posibilidad de que el Pleno pueda incidir en las mismas produciendo cualquier variación (art. 124.2), lo que podría incluir tanto su sustitución, su reorganización, como su extinción. Por el contrario, la existencia de las Comisiones especiales dependerá del asunto o materia que se le encomendó. Una vez concluido el informe del mismo, se extinguirá la Comisión salvo que, en el acuerdo de creación, el Pleno del Ayuntamiento hubiere acordado otra cosa (art. 124.3).

\section{La COMisión Especial de Cuentas}

A pesar de la mención de la Comisión especial de cuentas en la enumeración de los posibles órganos complementarios que realiza el ROF en su artículo 119, como ya se leyó con anterioridad, esta Comisión tiene en verdad carácter necesario, según el artículo 116 de la LB, que exige el preceptivo informe de la misma sobre las cuentas anuales y afirma con rotundidad el propio ROF ( la Comisión especial de cuentas es de existencia preceptiva...», art. 127), que incurre por ello en cierta incongruencia. Quizá la aplicación a la misma de todo el régimen jurídico de las Comisiones informativas sea la razón que indujo a este equívoco sistemático al redactor del ROF.

Su especialidad radica en el objeto que atiende, el «examen, estudio e informe de todas las cuentas, presupuestarias y extrapresupuestarias, que debe aprobar el Pleno» (art. 127.2). Deberá también emitir informe de todas las «reclamaciones, reparos u observaciones» que se realicen a la Cuenta general del Ayuntamiento durante el plazo de exposición al público (art. 193.3 de la Ley de haciendas locales). Además, si así se acuerda por el Pleno del Ayuntamiento, esta misma Comisión podrá hacer las veces de Comisión permanente para asuntos relativos a la economía y hacienda local, en cuyo caso, deberá asistir a la misma el Interventor del Ayuntamiento (según establece el art. 137 del ROF).

\section{Las Juntas Municipales de Distrito}

Estos órganos complementarios se fundan en un criterio de desconcentración territorial. Las grandes dimensiones de algunos Ayuntamientos pueden justificar una división de zonas o distritos, en cada 
uno de los cuales la gestión de determinados servicios, que no deban ser resueltos mediante criterios de unidad e integridad en el territorio municipal, se realice de forma, en cierto modo, autónoma o singular. El ROF declara esta intención de obtener una mejor gestión, en el primer artículo que dedica a las Juntas Municipales de Distrito, así como potenciar la participación ciudadana de dicha área (art. 128).

Pocas especificaciones más concreta el ROF. Como otros órganos complementarios ha de surgir de un acuerdo expreso del Pleno del Ayuntamiento [arts. 22.2.b) de la LB y 129 del ROF], calificado como reglamento, en el cual se definan sus elementos y aspectos básicos, a saber, el ámbito territorial del distrito, la composición de la Junta y funciones a desarrollar por la misma. También se declara que «se considerará a todos los efectos, parte integrante del Reglamento Orgánico», lo que trae como importante consecuencia la necesidad de que sea aprobado por el voto de la mayoría del número legal de miembros de la Corporación, según establece el artículo 47.3.a) de la LB.

El funcionamiento de la Junta se desenvolverá según las prescripciones contenidas en su reglamento y, de modo supletorio, por la aplicación de las reglas que rigen el funcionamiento del Pleno del Ayuntamiento (art. 139 del ROF). En la práctica, además, se ha consolidado una característica estructura de estas Juntas de Distrito. En su seno se diferencian, junto al Presidente, que será normalmente un Consejo designado por el Alcalde, con funciones representativas, el Concejal de Distrito, órgano de gestión y ejecución, y el Pleno del Distrito, integrado tanto por miembros del Consejo como por vecinos y representantes de asociaciones de vecinos o de consumidores y usuarios.

\section{LOS CONSEJOS SECTORIALES}

Otro de los órganos municipales presidido por el principio de participación ciudadana es el Consejo sectorial (como proclama el art. 130.1 del ROF). Frente a la participación según criterios territoriales, que preside la constitución de las Juntas Municipales de Distrito, en la creación de los Consejos sectoriales el criterio de participación tiene un carácter objetivo y material. Su función esencial es la redacción de informes y propuestas, es decir, sólo puede configurarse con un carácter consultivo. Sin lugar a dudas el artículo 130.2 del ROF establece que «desarrollarán exclusivamente funciones consultivas». Sin embargo, a pesar de que continúa el precepto «en relación con las iniciativas municipales», a mi juicio, el carácter participativo debe admitir que tanto el propio Consejo, como cualquiera de sus miembros, formulen iniciativas que puedan ser presentadas a los órganos municipales para su consideración. 
Pocas especificaciones contiene el ROF en relación a los Consejos sectoriales. En todo caso sujeta, como no puede ser de otro modo, la creación de los mismos a un acuerdo explícito del Pleno del Ayuntamiento (art. 131). Este acuerdo deberá contener las líneas para determinar su «composición, organización y ámbito de actuación». Con relación a su composición el Consejo deberá estar integrado por miembros de la Corporación, con participación de todas las distintas fuerzas políticas que tienen representación en el Pleno del Ayuntamiento (según la regla general, ya leída, contenida en el art. 20.3 de la LB), así como las asociaciones vecinales (art. 235 del ROF), de consumidores y usuarios, además de otros colectivos que puedan estar afectados por el ámbito material sobre el que extiende sus facultades de informe el Consejo. La Presidencia del Consejo corresponderá a un miembro de la Corporación designado por el Alcalde, que tiene libre facultad para este nombramiento y, por tanto, para su revocación (párrafo segundo del art. 131.1 del ROF). Sin embargo, esta regla general decae cuando el ámbito territorial sobre el que concreta su actuación el Consejo, se superpone o coincide con la extensión de una Junta Municipal de Distrito. En este caso, estabece el ROF de modo expreso que el Presidente deberá ser un miembro de la Junta (art. 131.2).

Con relación a su organización interna y funcionamiento, y ante la falta de otras prescripciones en el ROF, deberá estarse a lo que disponga el acuerdo del Pleno del Ayuntamiento de constitución del Consejo correspondiente, en el que goza, como con facilidad se puede deducir, de una amplia libertad para su configuración.

\section{LOS ÓRGANOS DESCONCENTRADOS Y DESCENTRALIZADOS}

La relación de órganos complementarios del artículo 119 del ROF concluye con la mención de la admisión de las tradicionales técnicas organizativas de la desconcentración y descentralización para el ámbito de la gestión de los servicios municipales, que no suponen sino el reconocimiento de la libertad de organización del Ayuntamiento. Sólo se establece en el ROF la necesidad de que surjan de un acuerdo del Pleno [en el art. 132, afirmación que respeta lo dispuesto en el art. 22.2.b) de la LB], así como su sujeción a las normas sobre la gestión de los servicios y al principio de economía organizativa (art. 133 del ROF). El específico tratamiento que se hace de estos órganos en el trabajo del profesor SOSA WAGNER, recogido en esta misma revista, me exime de realizar mayores comentarios. 


\section{LA LEGISLACION AUTONOMICA}

Tras la sentencia del Tribunal Constitucional relativa a la LB no puede discutirse, aunque sí debe criticarse, la preferencia de la legislación que dicte la Comunidad autónoma sobre organización complementaria municipal, al propio Reglamento Orgánico de la Corporación local. De existir en la Comunidad autónoma en la que radique el $\mathrm{Mu}$ nicipio una legislación especial sobre órganos complementarios, el reglamento deberá respetar o integrar dichos preceptos.

Hasta el momento, sólo son cuatro las Comunidades autónomas que han regulado aspectos del régimen local. Pero no todas han incidido en la organización complementaria de los Municipios. Así, la Ley Foral de Navarra de Administración Local (Ley 6/1990, de 2 de julio), se remite a lo dispuesto en la legislación estatal al aludir a la organización municipal (art. 8). En este sentido, en los «Comentarios a la Ley Foral de Administración Local de Navarra» (dirigidos por M. Razquin Lizarraga y A. Serrano Azcona, ed. Gobierno de Navarra, 1991, p. 59), A. ZuAZO MORENo al comentar el artículo 8 reconoce la inexistencia de especialidades organizativas en el ámbito foral, de ahí la libertad de los Municipios para su organización, y la aplicación supletoria de la legislación estatal.

Las diferencias que presentan el resto de las regulaciones, serán objeto de las siguientes líneas.

\section{LAS ESPECIALIDADES DE LA LEGISLACIÓN CATALANA}

La Ley del Parlamento catalán que regula el régimen local en dicha Comunidad autónoma (Ley 8/1987, de 15 de abril, municipal y de régimen local), después de concretar los órganos necesarios en el número 1 del artículo 46, en el que se incluye la Comisión especial de cuentas, establece en el número 2 que dicha organización se podrá completar con comisiones de estudio, informe o consulta, órganos de participación ciudadana u otros constituidos por el Municipio. En principio, no parecen existir especialidades, ante la potestativa creación de estos órganos que, sin gran dificultad, se pueden asimilar a los mencionados en el ROF como órganos complementarios. Sin embargo, es en la particular regulación de los mismos donde se ponen de manifiesto las diferencias.

Así, en primer lugar, con relación a las Comisiones, la ley impone la obligación de constituir Comisiones informativas en los Municipios de más de veinte mil habitantes (art. 57), que tienen la misma naturaleza y régimen que el descrito en la ya analizada legislación estatal. 
Pero destaca también otra diferencia, relativa a la composición de dichas Comisiones. Aunque se reconoce la participación de representantes de todos los grupos políticos en su seno, principio básico derivado de la LB, el número de miembros de la Comisión podrá determinarse bien por aplicación de la regla proporcional con la composición del Pleno del Ayuntamiento, bien establecer el mismo número de representantes de cada grupo, eso sí, con la ponderación del voto de los mismos (art. 56.3).

En segundo lugar, con relación a la regulación de los órganos de participación ciudadana, se admiten varias modalidades: por un lado, los órganos de gestión territorial desconcentrada y órganos territoriales de participación (que guardan cierta similitud con las Juntas Municipales de Distrito) y, por otro lado, los órganos de participación social (que pueden asemejarse a los Consejos sectoriales). La regulación de estos órganos complementarios de participación es más detallada que la contenida en el ROF. Así, los órganos de gestión territorial desconcentrada se integran por Concejales (en número no superior a un tercio del total), representantes de vecinos y de asociaciones ciudadanas; los órganos territoriales de participación deberán constituirse de forma obligatoria cuando en el grupo de población separada lo soliciten la mayoría de los vecinos y podrán ejercer tanto funciones deliberativas como ejecutivas en el ámbito de la gestión y utilización de los servicios sanitarios, deportivos y otros delegados por el Ayuntamiento.

\section{LAS ESPECIALIDADES DE LA LEGISLACIÓN MURCIANA}

La Ley de régimen local de la Región de Murcia (Ley 6/1988, de 25 de agosto) declara en el primer artículo que dedica a la organización de los Entes locales la autonomía organizativa de los mismos, con lo que las especialidades organizativas que esta Ley contiene sólo se aplicarán en defecto del particular Reglamento Orgánico, por lo que sólo tienen carácter supletorio (art. 21).

Como posibles órganos complementarios menciona esta Ley (en su art. 22): las Comisiones informativas, los grupos políticos (que en rigor, no son órganos complementarios de la Corporación, sino órganos de funcionamiento del Pleno del Ayuntamiento), los Concejales delegados de la Alcaldía, los Consejos sectoriales, los Alcaldes de barrio, pedanías o diputación y las Juntas de vecinos (que tampoco deben ser consideradas en propiedad como órganos complementarios, sino como Entes locales de ámbito inferior al Municipio, según los arts. 45 de la LB y 41 del TR). La regulación particular de cada uno de estos órganos no se aparta en exceso de la conocida regulación del ROF, sin perjuicio de ciertas peculiaridades que son a las que haré breve referencia. 
Con relación a las Comisiones informativas, que se configuran con la misma naturaleza y función consultiva que en el ROF, se respeta la participación de todas las fuerzas políticas con presencia en el Pleno del Ayuntamiento, pero la concreta integración, la determinación del número de representantes no sólo podrá ser proporcional a la relación de fuerzas en el Pleno, sino también determinarse un voto ponderado (art. 24).

Mayores precisiones contiene esta Ley al regular los «Alcaldes de barrio, pedanías y diputaciones», órgano similar a los representantes del Alcalde del ROF. En particular se puede destacar, como novedad frente a la legislación estatal el distinto ámbito territorial sobre el que estos vecinos extienden sus poderes de representación, derivado de las singulares y tradicionales estructuras territoriales murcianas. Así no sólo en los barrios y pedanías podrá el Alcalde nombrar un representante, sino también en las huertas o campos en los que se divida el Municipio (art. 37).

\section{La legislación de la COMUNidad CANARIA}

La Ley 14/1990, de 26 de julio, de régimen jurídico de las Administraciones Públicas de Canarias, después de declarar la autonomía municipal para regular su organización propia, con sujeción a la legislación básica del Estado (art. 61), declara las prescripciones de la misma de aplicación supletoria, ante la falta de Reglamento Orgánico municipal.

$\mathrm{Al}$ enumerar los órganos complementarios, presenta ya su naturaleza intrínseca en la clasificación que realiza de los mismos. Distingue, con distintas letras, los órganos de estudio y consulta [letra $b$ )], los órganos de gestión descentralizada [letra $c$ )], los órganos de gestión desconcentrada [letra $d$ )] y los órganos de participación vecinal [letra $d$ )]. Pero antes de destacar las particularidades frente al régimen general que los mismos presentan, debe subrayarse que, con anterioridad, se han calificado los Concejales delegados entre los órganos «básicos de gobierno y administración» [letra a) del mismo precepto]. La misma Ley contradice esta calificación, ya que tras citarlos alude a la posibilidad de su existencia, con los términos «en su caso».

Entre las especialidades de esta legislación pueden destacarse las siguientes. Con relación a las Comisiones informativas, se limita el número de miembros a un tercio de los componentes del Pleno (art. 83) y se garantiza, en todo caso, un representante de cada grupo político, aunque se reitera el respeto a la proporcionalidad de fuerzas del Pleno del Ayuntamiento (art. 84). Estas Comisiones se pueden estructurar o dividir en grupos o subcomisiones. Además, existen Comisiones espe- 
ciales, con un ámbito objetivo material concreto, entre las que se mencionan a la Comisión especial de cuentas, las Comisiones de colaboración con otras Administraciones Públicas, esta última configurada con carácter permanente (art. 88).

En la regulación de las Juntas Municipales de Distrito o Barrio destaca la posibilidad de que sólo se creen en aquellos Municipios con población superior a cincuenta mil habitantes (art. 96). Entre sus órganos, junto al Presidente, Gobierno y Pleno, existen Consejos de participación ciudadana integrados tanto por vecinos residentes en dicho distrito o barrio como por Entidades ciudadanas, que estén registradas convenientemente y tengan su domicilio en el distrito. En los $\mathrm{Mu}$ nicipios de menor población, podrán constituirse Consejos de barrio o de sector (art. 106), que se fundan también en la participación ciudadana de carácter desconcentrado.

En fin, tras el análisis de la legislación estatal y comunitaria, debe concluirse el reconocimiento práctico de la autonomía organizativa a los Municipios españoles (con la única excepción de las pocas particularidades vinculantes establecidas por la legislación catalana), por lo que éstos podrán libremente determinar los órganos que coadyuven al mejor ejercicio de sus funciones o a la prestación de los servicios municipales, con los únicos parámetros de respetar la organización básica establecida para todo el Estado y las específicas dimensiones y las necesidades del Municipio. No parece, pues, de momento, que la legislación de las Comunidades autónomas vaya a suponer un molesto dogal a la imaginación municipal. 